\title{
Small angle neutron scattering as sensitive tool to detect ligand-dependent shape changes in a plant lectin with $\beta$-trefoil folding and their dependence on the nature of the solvent
}

\author{
Lizhong He • Sabine André • Vasil M. Garamus • \\ Hans-Christian Siebert • Chunyan Chi • \\ Bernd Niemeyer • Hans-Joachim Gabius
}

Received: 2 December 2007 /Revised: 6 May 2008 / Accepted: 16 June 2008 / Published online: 11 July 2008

(C) The Author(s) 2008

\begin{abstract}
The galactoside-specific Viscum album L. agglutinin (VAA) is a potent biohazard akin to ricin and a mitogen for immune and tumor cells. These activities depend on cell surface binding to glycans. It is an open question whether the process of ligand binding alters the lectin's shape. Small angle neutron scattering (SANS) experiments revealed that the carbohydrate ligand lactose induced a decrease of the radius of gyration of dimeric VAA from $54.5 \pm 1$ to $49.5 \pm 1 \AA$ in water. Apparently, VAA in aqueous solution and at the concentrations tested at $3.6 \mathrm{mg} / \mathrm{ml}$ and above adopts a compacted structure as response to ligand binding. In contrast to the behavior in aqueous solution, lactose binding in DMSO resulted in an
\end{abstract}

\section{He $(\bowtie)$}

Centre for Biomolecular Engineering,

Australian Institute for Bioengineering and Nanotechnology,

The University of Queensland,

St Lucia, QLD 4072, Australia

e-mail: 1.he@uq.edu.au

S. André $\cdot$ H.-C. Siebert $\cdot$ H.-J. Gabius Institute for Physiological Chemistry,

Faculty of Veterinary Medicine,

Ludwig-Maximilians-University Munich,

Veterinärstr. 13,

80539 Munich, Germany

V. M. Garamus • B. Niemeyer

GKSS Research Centre,

Max-Planck-Strasse 1,

21502 Geesthacht, Germany

C. Chi

Max-Planck-Institute for Polymer Research,

Ackermannweg 10,

55128 Mainz, Germany increase of the lectin's radius of gyration from $49 \pm 1$ to $55.5 \pm 1 \AA$. Because shape changes may be reflected in the thermostability of the protein, this parameter was examined by activity assays of protein exposed to $60^{\circ} \mathrm{C}$ and $70^{\circ} \mathrm{C}$ and by differential scanning calorimetry (DSC). In line with the lactose-induced conformational alterations revealed by the SANS experiments, lactose presence enhanced the thermostability of VAA in water. Thus, binding of the carbohydrate ligand in solution can entail changes in shape and thermostability in the case of the tested plant lectin.

Keywords Agglutinin - Lectin · Ligand · Small angle neutron scattering $\cdot$ Thermostability $\cdot$ Toxin

\section{Introduction}

Lectins (proteins with a carbohydrate-binding module without enzymatic activity acting on the ligand) exert a wide range of physiological functions such as contact formation in fertilization, regulation of cell growth including mitogenic or pro- and anti-apoptotic activities, cell adhesion and migration, endocytosis, glycoprotein folding and quality control as well as immune mediator production/ release [1-5]. Efficient cross-linking of cell surface ligands after specific binding as prerequisite for signaling, however, may not be the only consequence of the binding process $[5,6]$. It could also be possible that the lectin responds to the occupation of the carbohydrate-binding site with a local conformational or even a global shape change. Ligand binding might hereby act as a molecular switch, controlling other types of interaction by protein-protein (or lipid) recognition, akin to a posttranslational modification. This 
concept opposes current evidence on lectin structures from crystallography, for example the key-like accommodation of the ligand into the binding site by diffusion into crystals [2]. In order to examine the concern that the spatial constraints imposed in a crystal might hamper detection of ligand-induced structural changes a sensitive approach to spot shape changes for proteins in solution should be tested.

Small angle scattering (SAS) using X-ray (SAXS) or neutron (SANS) beams is a means toward this aim, delineating the solution structure of biological macromolecules at a fairly low resolution (typically $1 \mathrm{~nm}$ ) [7]. Its monitoring allows structural characterization under physiological conditions and detection of changes as response to experimental parameters (e.g. ionic strength, temperature and ligand concentration). The scattering curves can be processed using the ab initio method to calculate the proteins' shape [8]. Because hydrodynamic parameters such as sedimentation and diffusion coefficients can be predicted from protein structures $[9,10]$, respective methods (e.g. ultracentrifugation or dynamic light scattering) play a valuable role in validating structure model obtained from SAS data [11].

We have previously introduced SANS to lectin research. It indeed proved reliable and sensitive to analyze a lectin's shape in solution and to pick up ligand-dependent effects on this parameter, using human galectin-1 as proof-ofprinciple case [12]. In essence, lactose binding led to a significant reduction of the radius of gyration of this protein with the $\beta$-sandwich fold [12]. In the course of examining solvent effects on the human lectin in the next step, we also processed a second lectin. Initial evidence was provided for an alteration of the aggregation status of a plant agglutinin/ toxin when using water and the aprotic solvent dimethyl sulfoxide (DMSO) as solvent [12]. Of note, the studied galactoside-specific plant lectin has a $\beta$-trefoil folding $[13$, 14]. It thus differs markedly from the galectin with its antiparallel $\beta$-strand pattern [15]. This structural difference prompted the question as to whether occupation of the lectin site will also trigger a shape alteration in this case.

Thus, we purified the galactoside-specific agglutinin/ toxin from Viscum album L. (VAA; also referred to as viscumin or ML-1), different from a second mistletoe lectin specific for $N$-acetylgalactosamine [16, 17]. So far, its ligand binding had been analyzed by atomic force microscopy, Scatchard analysis, surface plasmon resonance and titration calorimetry $[18-20]$. We herein resolve the question as to whether ligand binding has a bearing on the shape of this lectin with the $\beta$-trefoil fold. Moreover, because this lectin maintained binding capacity in aprotic solvent [21], we studied shape parameters also in DMSO. Our data reveal remarkable shape alterations in response to occupation of the carbohydrate-binding site in water and in DMSO. In line with this effect, the lectin's thermostability is increased by ligand presence.

\section{Material and methods}

Materials

Lactose and $\left[\mathrm{D}_{6}\right]$ DMSO (deuteration grade $>99.9 \%$ ) were obtained from Sigma (Steinheim, Germany). $\mathrm{D}_{2} \mathrm{O}$ (deuteration grade $>99.8 \%$ ) was purchased from Merck (Darmstadt, Germany). All other reagents were of analytical grade.

\section{Sample preparation}

VAA was purified from extracts of dried mistletoe leaves using affinity chromatography on lactosylated Sepharose 4B, obtained by ligand conjugation after resin activation with divinyl sulfone, as the crucial step [22]. Analyses of purity and activity were performed by gel filtration, oneand two-dimensional gel electrophoresis, haemagglutination, solid-phase and cell binding/growth assays [20, 23-25]. Prior to SANS measurements, $\mathrm{H}_{2} \mathrm{O}$ of freshly prepared VAA solutions in phosphate buffer (PB; $20 \mathrm{mM}$, $\mathrm{pH} 7.2, \mathrm{H}_{2} \mathrm{O}$ ) was exchanged to $\mathrm{D}_{2} \mathrm{O}$ by adding $\mathrm{PB}$ in $\mathrm{D}_{2} \mathrm{O}$ ( $20 \mathrm{mM}, \mathrm{pD}$ 7.2), followed by a step using a Millipore centrifugal concentrator with a $10 \mathrm{kDa} \mathrm{MW}$ cut-off. The procedure was repeated three times to ensure that the remaining contents of $\mathrm{H}_{2} \mathrm{O}$ was less than $0.5 \%$. This buffer exchange method was instrumental for preparing highquality VAA samples in $\mathrm{D}_{2} \mathrm{O}$ with minimum extent of aggregation. To prepare VAA solutions in DMSO, the protein was first lyophilized and then dissolved in neat DMSO. $\left[\mathrm{D}_{6}\right] \mathrm{DMSO}$ was employed for SANS experiments, while regular DMSO was the solvent when performing differential scanning calorimetry (DSC). The protein solutions were routinely centrifuged prior to measurements to remove any insoluble material.

\section{SANS experiments}

The SANS experiments were performed on the instrument SANS-1 at the Geesthacht Neutron Facility GeNF, Geesthacht, Germany [26]. The range of the modules of the scattering vectors $q(q=4 \pi \sin \theta / \lambda$, where $2 \theta$ is the scattering angle and $\lambda$ is the wavelength) from 0.01 to $0.25 \AA^{-1}$ was covered by using four sample-to-detector distances (from 0.7 to $7 \mathrm{~m}$ ). The neutron wavelength $\lambda$ was $8.1 \AA$ (measured by routine time-of-flight experiments) with a wavelength resolution of $10 \%$ (full width at halfmaximum value). The two-dimensional isotropic scattering patterns were azimuthally averaged, converted to an absolute scale and corrected for detector efficiency by using the incoherent scattering pattern of pure water [27]. The background from the solvent and sample cell was subtracted from the raw patterns by conventional procedures [28]. Scattering data were processed by indirect Fourier 
transformation (IFT), a model-independent method, to obtain the radii of gyration of the particles and their pair-distance distribution function $p(r)$ [29]. The IFT method also provided the scattering intensity at the zero angle to calibrate the molecular weight of the protein, using bovine serum albumin (BSA) at a concentration of $5 \mathrm{mg} / \mathrm{ml}$ as reference.

Heat treatment and activity assays

Lyophilized VAA was dissolved in phosphate-buffered saline (PBS) or PBS containing either the ligand lactose or the inert osmolarity control mannose at a concentration of $20 \mathrm{mM}$. Treatment at three different temperatures ( $\mathrm{RT}=$ room temperature, $60^{\circ} \mathrm{C}$ and $70^{\circ} \mathrm{C}$ ) lasted $10 \mathrm{~min}$ in a volume of $50 \mu \mathrm{l}$. Following brief centrifugation lectin was adsorbed to the plastic surface of microtiter plate wells at $100 \mathrm{ng} / 50 \mu \mathrm{l}$ for $12 \mathrm{~h}$ at $4^{\circ} \mathrm{C}$, remaining sugar was thoroughly removed by a series of washing steps, and the binding assay using biotinylated asialofetuin as probe was carried out as described previously [30].

\section{Differential scanning calorimetry}

The thermostability of the lectin in DMSO was examined in a Mettler Toledo star system. The protein solution was heated from 20 to $120^{\circ} \mathrm{C}$ at a scan rate of $0.5^{\circ} \mathrm{C} / \mathrm{min}$. After initial heating, the samples were cooled and then reheated to determine whether the transition was reversible.

\section{Results and discussion}

In the first series of experiments we assessed the lectin's radius of gyration at three different concentrations to

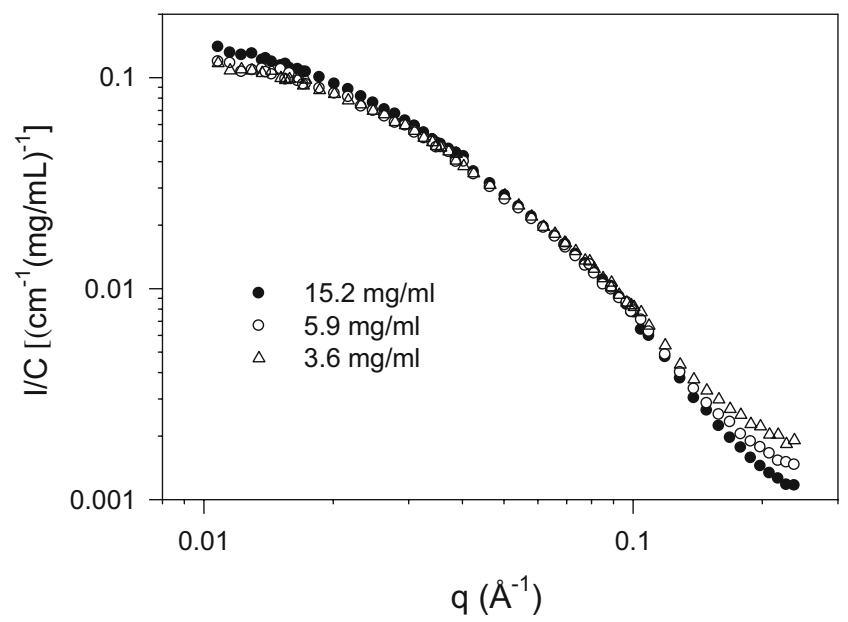

Fig. 1 Normalized SANS spectra of VAA in phosphate buffer $\left(20 \mathrm{mM}, \mathrm{pD} 7.2, \mathrm{D}_{2} \mathrm{O}\right)$ at different protein concentrations. The spectra were normalized by dividing scattering intensity I with protein concentration $\mathrm{C}$
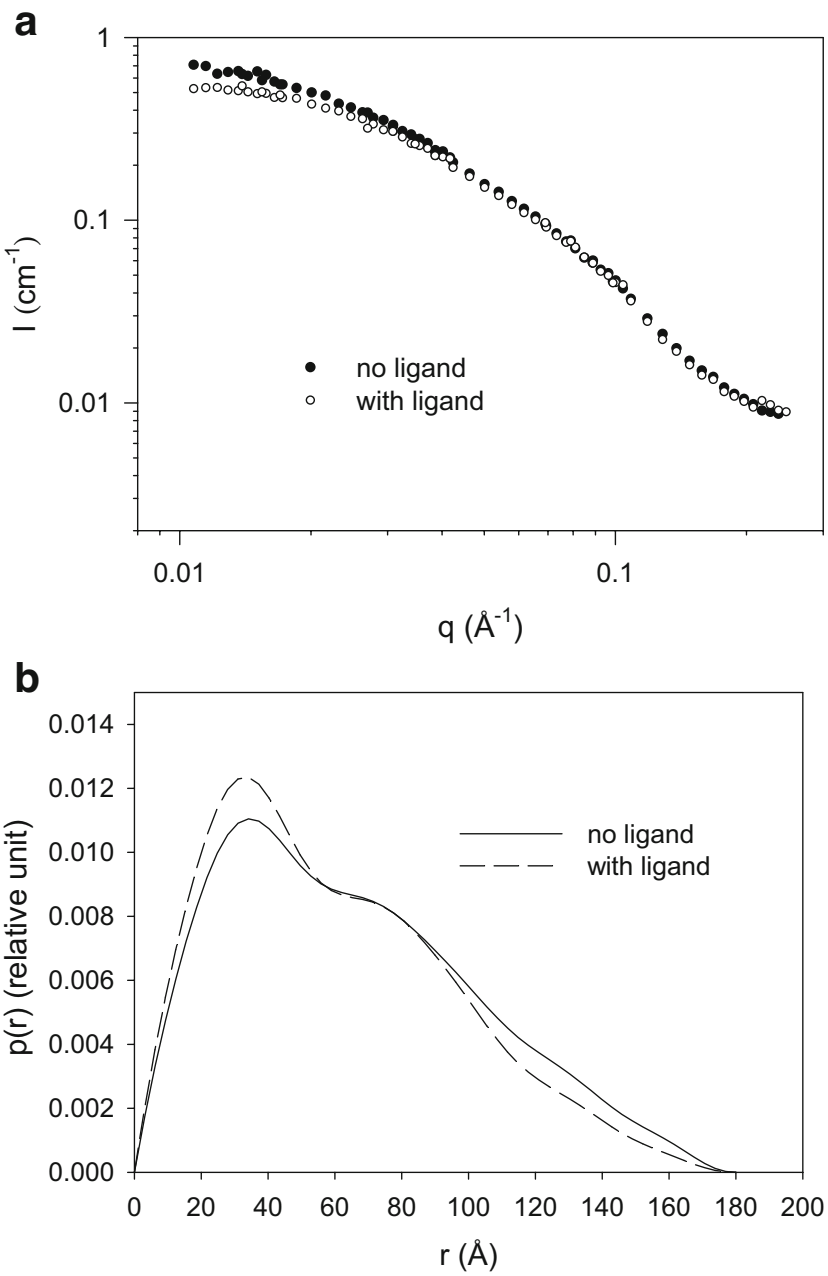

Fig. 2 Effect of the ligand on SANS spectra of VAA in phosphate buffer. a SANS spectra at $5.9 \mathrm{mg} / \mathrm{mL}$ VAA in $20 \mathrm{mM}$ phosphate buffer (pD 7.2, $\mathrm{D}_{2} \mathrm{O}$ ), in the absence and presence of $20 \mathrm{mM}$ lactose. b Pair distance distribution $p(r)$ function obtained from the corresponding scattering curves in a

establish a firm basis for measurements in the presence of ligand. Confirming previous data sets [12], the IFT analysis of spectra shown in Fig. 1 gave almost identical data at protein concentrations of $3.6 \mathrm{mg} / \mathrm{mL}(54 \pm 1 \AA)$ and $5.9 \mathrm{mg} /$ $\mathrm{mL}(54.5 \pm 1 \AA)$. The radius of gyration at $15.2 \mathrm{mg} / \mathrm{mL}$ was slightly increased $(56 \pm 1 \AA)$. This comparison revealed that a protein concentration of $5.9 \mathrm{mg} / \mathrm{mL}$ is within the dilute region, and there were no significant interparticle interactions hindering IFT analysis.

Using BSA at a concentration of $5 \mathrm{mg} / \mathrm{mL}$ as a reference, the molecular weight of VAA was estimated to be $135 \mathrm{kD}$ by comparing scattering intensities at zero angle. In line with literature data $[13,20,31]$ and our gel filtration analysis of aliquots run in parallel the lectin consistently formed $(A B)_{2}$ dimers ( $A=$ toxin subunit, $B=$ lectin subunit) under these conditions. This confirms that the dimer structure seen in crystals $[13,14]$ was not due to a crystal packing force. 

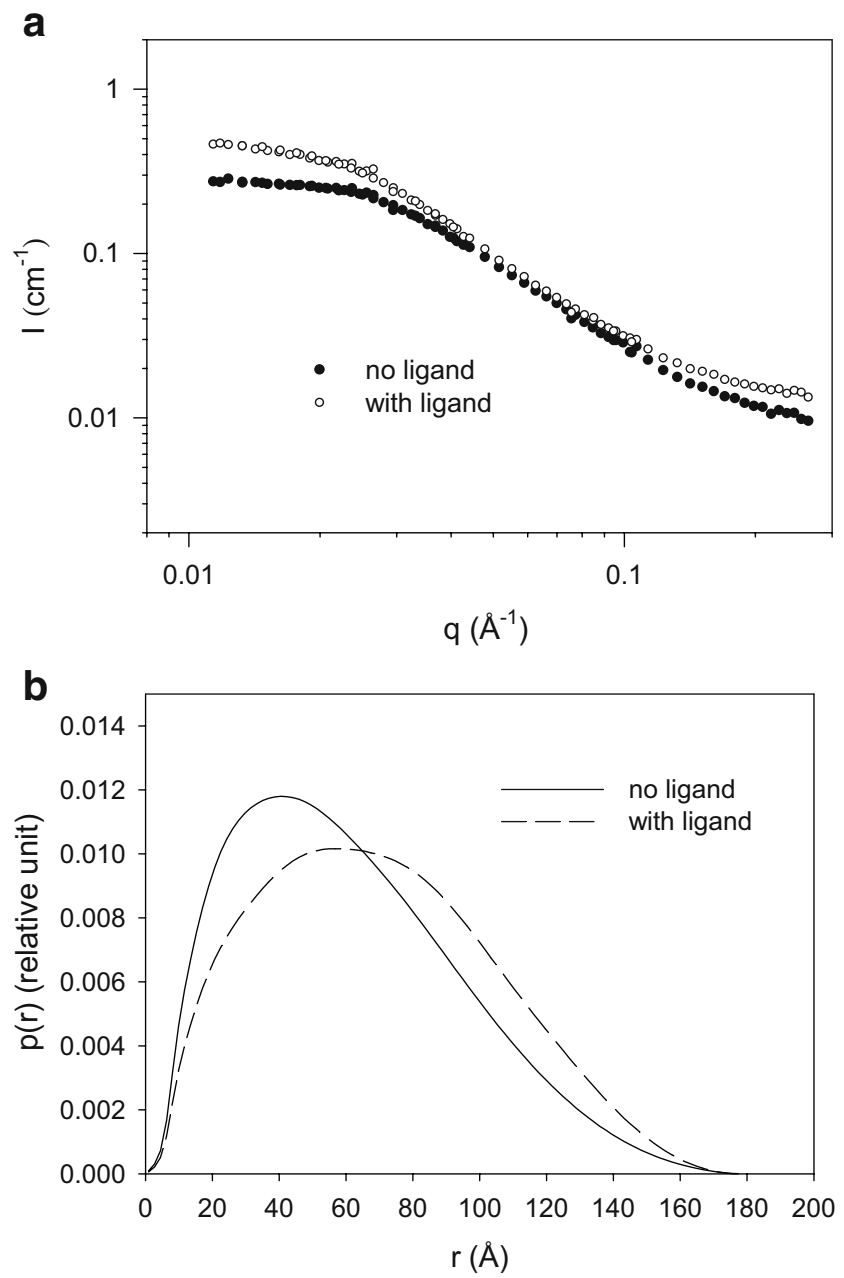

Fig. 3 Effect of the ligand on SANS spectra of VAA in DMSO. a SANS spectra at $9.6 \mathrm{mg} / \mathrm{mL}$ VAA in $\left[\mathrm{D}_{6}\right] \mathrm{DMSO}$, in the absence and presence of $20 \mathrm{mM}$ lactose. b Pair distance distribution $p(r)$ function obtained from the corresponding scattering curves in a

The effect of ligand binding on SANS spectra at a VAA concentration of $5.9 \mathrm{mg} / \mathrm{mL}$ in PB is shown in Fig. 2a. The scattering intensities of VAA at low angle were clearly decreased by adding $20 \mathrm{mM}$ lactose. IFT analysis gave a radius of gyration of $49.5 \pm 1 \AA$. Comparison of the $p(r)$ function (Fig. 2b) revealed that VAA in aqueous solution has a more compact structure after accommodating the ligand than before, effectively a decrease by $5 \AA$. The maximum distances within a protein particle at both conditions were around $175 \AA$. This value was close to the maximum length $(176 \AA)$ calculated from the dimensions $(157 \times 63 \times 48 \AA)$ of a VAA dimer in crystals [14]. Availability of data on hydrodynamic properties by ultracentrifugation [24] facilitates further comparison. A modified Svedberg equation can be used to predict the sedimentation coefficient from the molecular weight and the diffusion coefficient [32]. Using a previously estab-

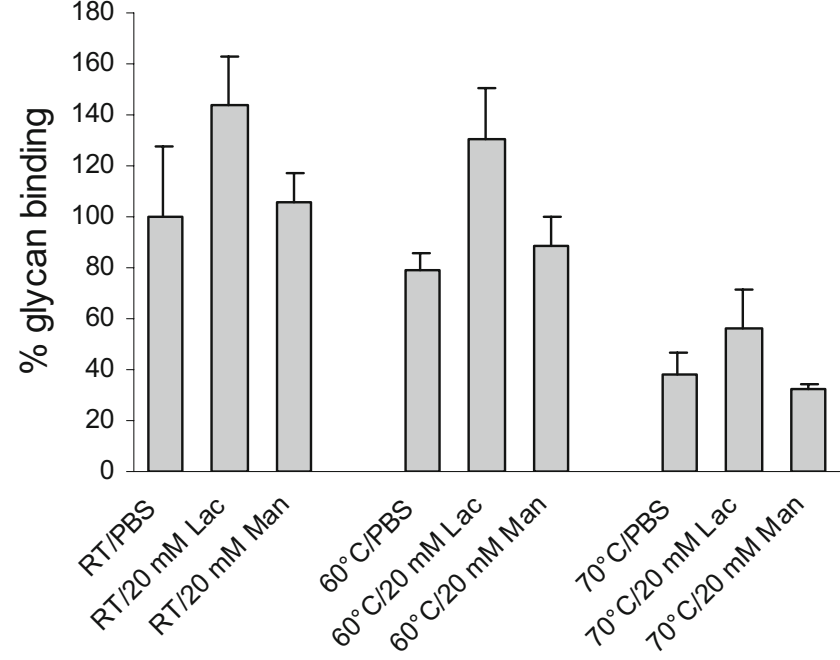

Fig. 4 Effect of ligand presence (20 mM lactose) on thermostability of VAA, revealed by glycan-binding capacity in solid-phase assays. Prior to activity assays, the samples were treated for $10 \mathrm{~min}$ at room temperature (RT, left panel), at $60^{\circ} \mathrm{C}$ (middle panel), and $70^{\circ} \mathrm{C}$ (right panel). $20 \mathrm{mM}$ D-mannose worked as inert osmolarity control in parallel

lished correlation [10], the diffusion coefficient of VAA can be estimated from its molecular weight $(135 \mathrm{kDa})$ and radius of gyration $(54.5 \AA$ without ligand and $49.5 \AA$ with ligand). SANS data thus predicted the sedimentation coefficients of $5.8 \mathrm{~S}$ and $6.1 \mathrm{~S}$ for VAA in the absence and presence of ligand, respectively. These numbers are close to the experimental data of the VAA dimer obtained by ultracentrifugation [24].

Having detected an effect of ligand presence on VAA's shape in water, we next examined this parameter for VAA in DMSO. As demonstrated previously [12, 21], VAA was
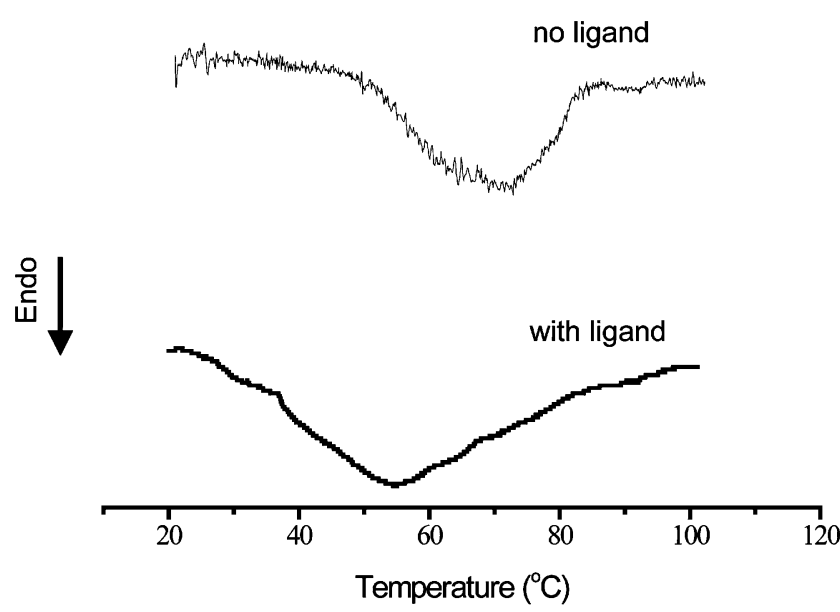

Fig. 5 DSC spectra of VAA in DMSO in the absence and presence of ligand (100 mM lactose). The temperature of a solution containing $10 \mathrm{mg} / \mathrm{mL}$ VAA in DMSO was raised from 20 to $120^{\circ} \mathrm{C}$ at a scan rate of $0.5^{\circ} \mathrm{C} / \mathrm{min}$ 
readily brought into solution in the aprotic solvent and its tendency for aggregation reduced. As shown in Fig. 3a, ligand presence also altered the SANS spectra of the lectin in DMSO. In contrast to the behavior in water, the scattering intensities at low angle significantly increased when lactose was present, and the radius of gyration of VAA was increased from $49 \pm 1 \AA$ to $55.5 \pm 1 \AA$. The $p(r)$ function shown in Fig. $3 \mathrm{~b}$ intimates that the protein adopted a "loose" structure upon binding of lactose in DMSO (dielectric constant of 46.7 significantly lower than that of water at 78.4). Consequently, we assumed that the structural change (compaction or loosening) might have a bearing on the lectins's capacity to withstand thermal denaturation.

To verify this concept, we tested VAA activity in water after heat treatment in the absence and presence of the ligand lactose. It can be seen in Fig. 4 that the presence of $20 \mathrm{mM}$ lactose during heat treatment enhanced extent of glycan binding in the assay, suggesting that VAA in the presence of lactose has increased thermostability. Mannose used as negative control showed negligible effects on thermostability. In contrast to a stabilizing effect of lactose in water associated with adopting a compacted shape, the SANS data led to expect that lactose binding renders the protein less thermostable in the aprotic solvent. Indeed, DSC data fulfilled this prediction. After initial heating of the protein-containing solution from 20 to $120^{\circ} \mathrm{C}$ at a scan rate of $0.5^{\circ} \mathrm{C} / \mathrm{min}$, the samples were cooled and then reheated to determine whether the transition is reversible. In the absence of the ligand, the initial heating yielded a maximum temperature $T_{\mathrm{m}}$ (temperature at the peak) with a value of $73.2^{\circ} \mathrm{C}$. A repeated cycle gave a baseline, suggesting that the protein was irreversibly denatured after the initial heating (for clarity, only the initial heating curve is shown in Fig. 5). Strikingly, adding $100 \mathrm{mM}$ lactose resulted in a significant decrease of the $T_{\mathrm{m}}$ value to $55^{\circ} \mathrm{C}$.

\section{Conclusions}

Presence of lactose reduced the radius of gyration of VAA in water, with the ensuing consequence of increased thermostability. In DMSO, where the ligand-free protein is subject to reduction in radius of gyration, lactose binding accounts for an increase of this parameter, with ensuing decrease in thermostability. The detected activity of the ligand to act as modulator of shape may have implications for cellular toxin uptake after glycan binding and design of inhibitors for this potential biohazard [25, 33]. Also, these data present a challenge to molecular modeling of protein dynamics that had recently moved to flexible ligand docking for a galectin [34].
Acknowledgement The financial support by an EC Marie Curie Research Training Network grant (contract MRTN-CT-2005-019561), the Verein zur Förderung des biologisch-technologischen Fortschritts in der Medizin e. V. and the research initiative LMUexcellent is gratefully acknowledged as are insightful discussions with Dr. B. Friday and Dr. S. Namirha.

Open Access This article is distributed under the terms of the Creative Commons Attribution Noncommercial License which permits any noncommercial use, distribution, and reproduction in any medium, provided the original author(s) and source are credited.

\section{References}

1. Gabius, H.-J.: Animal lectins. Eur. J. Biochem. 243, 543-576 (1997)

2. Lis, H., Sharon, N.: Lectins: carbohydrate-specific proteins that mediate cellular recognition. Chem. Rev. 98, 637-674 (1998)

3. Rüdiger, H., Siebert, H.-C., Solís, D., Jiménez-Barbero, J., Romero, A., von der Lieth, C.-W., Díaz-Mauriño, T., Gabius, H.-J.: Medicinal chemistry based on the sugar code: fundamentals of lectinology and experimental strategies with lectins as targets. Curr. Med. Chem. 7, 389-416 (2000)

4. Gabius, H.-J., Siebert, H.-C., André, S., Jiménez-Barbero, J., Rüdiger, H.: Chemical biology of the sugar code. ChemBioChem 5, 741-764 (2004)

5. Gabius, H.-J.: Cell surface glycans: the why and how of their functionality as biochemical signals in lectin-mediated information transfer. Crit. Rev. Immunol. 26, 43-79 (2006)

6. Villalobo, A., Nogales-González, A., Gabius, H.-J.: A guide to signaling pathways connecting protein-glycan interaction with the emerging versatile effector functionality of mammalian lectins. Trends Glycosci. Glycotechnol. 18, 1-37 (2006)

7. Koch, M.H.J., Vachette, P., Svergun, D.I.: Small-angle scattering: a view on the properties, structures and structural changes of biological macromolecules in solution. Quart. Rev. Biophys. 36, 147-227 (2003)

8. Svergun, D.I.: Restoring low resolution structure of biological macromolecules from solution scattering using simulated annealing. Biophys. J. 76, 2879-2886 (1999)

9. Garcia de la Torre, J., Huertas, M.L., Carrasco, B.: Calculation of hydrodynamic properties of globular proteins from their atomiclevel structure. Biophys. J. 78, 719-730 (2000)

10. He, L., Niemeyer, B.: A novel correlation for protein diffusion coefficients based on molecular weight and radius of gyration. Biotechnol. Progr. 19, 544-548 (2003)

11. Hamada, D., Higurashi, T., Mayanagi, K., Miyata, T., Fukui, T., Iida, T., Honda, T., Yanagihara, I.: Tetrameric structure of thermostable direct hemolysin from Vibrio parahaemolyticus revealed by ultracentrifugation, small-angle X-ray scattering and electron microscopy. J. Mol. Biol. 365, 187-195 (2007)

12. He, L., André, S., Siebert, H.-C., Helmholz, H., Niemeyer, B., Gabius, H.-J.: Detection of ligand- and solvent-induced shape alterations of cell-growth-regulatory human lectin galectin-1 in solution by small angle neutron and x-ray scattering. Biophys. J. 85, 511-524 (2003)

13. Sweeney, E.C., Tonevitsky, A.G., Palmer, R.A., Niwa, H., Pfüller, U., Eck, J., Lentzen, H., Agapov, I.I., Kirpichnikov, M.P.: Mistletoe lectin I forms a double trefoil structure. FEBS Lett. 431, 367-370 (1998)

14. Niwa, H., Tonevitsky, A.G., Agapov, I.I., Saward, S., Pfüller, U., Palmer, R.A.: Crystal structure at $3 \AA$ of mistletoe lectin I, a 
dimeric type-II ribosome-inactivating protein, complexed with galactose. Eur. J. Biochem. 270, 2739-2749 (2003)

15. López-Lucendo, M.F., Solís, D., André, S., Hirabayashi, J., Kasai, K.-I., Kaltner, H., Gabius, H.-J., Romero, A.: Growth-regulatory human galectin-1: crystallographic characterization of the structural changes induced by single-site mutations and their impact on the thermodynamics of ligand binding. J. Mol. Biol. 343, 957-970 (2004)

16. Luther, P., Becker, H.: Die Mistel. Botanik, Lektine, medizinische Anwendung. Springer, Berlin (1987)

17. Hajto, T., Hostanska, K., Gabius, H.-J.: Modulatory potency of the galactoside-specific lectin from mistletoe extract on the host defense system in vivo in rabbits and patients. Cancer Res. 49, 4803-4808 (1989)

18. Dettmann, W., Grandbois, M., André, S., Benoit, M., Wehle, A.K., Kaltner, H., Gabius, H.-J., Gaub, H.E.: Differences in zero-force and force-driven kinetics of ligand dissociation from $\beta$-galactoside-specific proteins (plant and animal lectins, immunoglobulin G) monitored by plasmon resonance and dynamic single molecule force microscopy. Arch. Biochem. Biophys. 383, $157-170(2000)$

19. Jiménez, M., André, S., Siebert, H.-C., Gabius, H.-J., Solís, D.: ABtype lectin (toxin/agglutinin) from mistletoe: differences in affinity of the two galactoside-binding Trp/Tyr-sites and regulation of their functionality by monomer/dimer equilibrium. Glycobiology 16, 926-937 (2006)

20. André, S., Kožár, T., Schuberth, R., Unverzagt, C., Kojima, S., Gabius, H.-J.: Substitutions in the N-glycan core as regulators of biorecognition: the case of core-fucose and bisecting GlcNAc moieties. Biochemistry 46, 6984-6995 (2007)

21. Siebert, H.-C., André, S., Asensio, J.L., Cañada, F.J., Dong, X., Espinosa, J.F., Frank, M., Gilleron, M., Kaltner, H., Kožár, T., Bovin, N.V., von der Lieth, C.-W., Vliegenthart, J.F.G., JiménezBarbero, J., Gabius, H.-J.: A new combined computational and NMR-spectroscopical strategy for the identification of additional conformational constraints of the bound ligand in an aprotic solvent. ChemBioChem 1, 181-195 (2000)

22. Gabius, H.-J.: Influence of type of linkage and spacer on the interaction of $\beta$-galactoside-binding proteins with immobilized affinity ligands. Anal. Biochem. 189, 91-94 (1990)

23. Gabius, H.-J., Darro, F., Remmelink, M., André, S., Kopitz, J., Danguy, A., Gabius, S., Salmon, I., Kiss, R.: Evidence for stimulation of tumor proliferation in cell lines and histotypic cultures by clinically relevant low doses of the galactoside-binding mistletoe lectin, a component of proprietary extracts. Cancer Invest. 19, 114-126 (2001)
24. Jiménez, M., Sáiz, J.L., André, S., Gabius, H.-J., Solís, D.: Monomer/dimer equilibrium of the AB-type lectin from mistletoe enables combination of toxin/agglutinin activities in one protein: analysis of native and citraconylated proteins by ultracentrifugation/gel filtration and cell biological consequences of dimer destabilization. Glycobiology 15, 1386-1395 (2005)

25. André, S., Pei, Z., Siebert, H.-C., Ramström, O., Gabius, H.-J.: Glycosyldisulfides from dynamic combinatorial libraries as $O$ glycoside mimetics for plant and endogenous lectins: their reactivities in solid-phase and cell assays and conformational analysis by molecular dynamics simulations. Bioorg. Med. Chem. 14, 6314-6326 (2006)

26. Stuhrmann, H.B., Burkhardt, N., Dietrich, G., Junemann, R., Meerwinck, W., Schmitt, M., Wadzack, J., Willumeit, R., Zhao, J., Nierhaus, K.H.: Proton and deuteron spin targets in biological structure research. Nucl. Instrum. A 356, 124-132 (1995)

27. Wignall, G.D., Bates, F.S.: Absolute calibration of small-angle neutron-scattering data. J. Appl. Crystallogr. 20, 28-40 (1987)

28. Cotton, J.P.: Introduction to scattering experiments. In: Lindner, P., Zemb, T. (eds.) Neutron, X-Ray and Light Scattering: Introduction to an Investigative Tool for Colloid and Polmeric Systems, pp. 19-33. Elsevier, Amsterdam (1991)

29. Svergun, D.I.: Determination of the regularization parameter in indirect-transform methods using perceptual criteria. J. Appl. Crystallogr. 25, 495-503 (1992)

30. Galanina, O.E., Kaltner, H., Khraltsova, L.S., Bovin, N.V., Gabius, H.-J.: Further refinement of the description of the ligand-binding characteristics for the galactoside-binding mistletoe lectin, a plant agglutinin with immunomodulatory potency. J. Mol. Recognit. 10, 139-147 (1997)

31. Olsnes, S., Stirpe, F., Sandvig, K., Pihl, A.: Isolation and characterization of viscumin, a toxic lectin from Viscum album L. (mistletoe). J. Biol. Chem. 257, 13263-13270 (1982)

32. Lebowitz, J., Lewis, M.S., Schuck, P.: Modern analytical ultracentrifugation in protein science: a tutorial review. Protein Sci. 11, 2067-2079 (2002)

33. André, S., Maljaars, C.E.P., Halkes, K.M., Gabius, H.-J., Kamerling, J.P.: Discovery of galectin ligands in fully randomized combinatorial one-bead-one-compound glyco(peptide) libraries. Bioorg. Med. Chem. Lett. 17, 793-798 (2007)

34. Wu, A.M., Singh, T., Liu, J.-H., Krzeminski, M., Russwurm, R., Siebert, H.-C., Bonvin, A.M.J.J., André, S., Gabius, H.-J.: Activity-structure correlations in divergent lectin evolution: fine specificity of chicken galectin CG-14 and related CG-16. Glycobiology 17, 165-184 (2007) 